\title{
PERBANDINGAN EFEKTIFITAS PENYULUHAN KESEHATAN GIGI METODE DONGENG (STORYTELLING) DENGAN METODE BERMAIN PERAN (ROLE PLAY) PADA SISWA KELAS 3 SEKOLAH DASAR
}

\author{
Resti Khairani $^{1}$, Nur Indrawati Lipoeto ${ }^{2}$, Bambang Ristiono ${ }^{1}$
}

\begin{abstract}
Background and purpose: Dental caries is a problem that often arises in children. One contributing factor is the child's behavior. Behavior began to form of knowledge, and knowledge to stimulate a change in attitude and action. The knowledge of elementary school children about dental health at the level of bad and less. Children have characteristics consistent with the cognitive development, is one of the aspects to be considered in determining the appropriate target education and the education methods will be used. The purpose of this education is to see the difference in the effectiveness of storytelling method and role play method as an method of dental and oral health education on a 3rd grade elementary school. Material and Methods: The research method was quasi experimental with pretest and posttest design. Samples were taken by using purposive sampling technique with a sample of 54 students in grades 3 SDN 22 Andalas Padang. The samples were divided into 2 groups with different treatment, 27 students with storytelling method and 27 students with role play method. The level of knowledge was measured through filled questionnaires before and after education. Analysis of the data used is paired T test and independent $T$ test $(p<0.05)$. Results and conclusions: results analysis of test showed a significant increase in knowledge $(p<0.05)$ after being given an education on each method with a significance value of 0.000. The average change knowledge in the storytelling method was 14.26 \pm 4.09 while the role play method was $17.96 \pm 3.99$. There are differences in effectiveness between the two methods of education to increase knowledge with a significance value of 0.001 ( $p<0.05)$. The conclusion of this study is role play as a method of dental and oral health education is an effective method to increasing knowledge.
\end{abstract}

Keywords:role play, storytelling, education, elementary school students

Affiliasi penulis : 1. Fakultas Kedokteran Gigi Universitas Andalas, 2. Fakultas Kedokteran Universitas Andalas

Korespondensi: Resti Khairani, email: khairaniresti95@gmail.com Telp:081276913196

\section{PENDAHULUAN}

Kesehatan gigi dan mulut merupakan bagian dari kesehatan jasmani yang tidak dapat dipisahkan satu dan lainnya karena akan mempengaruhi tubuh secara keseluruhan ${ }^{1}$. Dengan memiliki gigi dan mulut yang sehat, beberapa aktifitas seperti berbicara, makan, dan bersosialisasi tidak akan terganggu karena terhindar dari rasa sakit, tidak nyaman, dan malu. Kenyataannya sampai saat ini tingkat kesehatan gigi dan mulut masyarakat Indonesia masih rendah. Hal ini terlihat dari peningkatan angka penduduk Indonesia yang memiliki masalah gigi dan mulut pada tahun 2007 sebanyak 23\% sedangkan pada tahun 2013 sebanyak 26\% ${ }^{2}$. Hasil Riset Kesehatan Dasar tahun 2013, menunjukkan kebiasaan 
menyikat gigi dengan benar penduduk Indonesia hanya 2,3\%, dan rata-rata indeks DMF-T Indonesia adalah 4,6. Salah satu prevalensi penyakit gigi dan mulut yang tinggi adalah karies gigi. Studi epidemiologi mengenai karies menunjukkan bahwa prevalensi karies meningkat pada negara berkembang ${ }^{3}$. Berdasarkan Riset Kesehatan Dasar tahun 2007, menunjukkan bahwa prevalensi nasional karies aktif adalah 43,4\% dan pengalaman karies sebesar 67,2\%. Diprovinsi Sumatera Barat prevalensi karies aktif mencapai $41,6 \%$ dan pengalaman karies sebesar $70,6 \%{ }^{4}$.

$$
\text { Karies gigi merupakan }
$$

permasalahan gigi yang sering timbul tidak hanya pada orang dewasa tetapi juga dialami oleh anak-anak. Oral hygiene yang buruk dapat menjadi salah satu faktor resiko terjadinya karies. Di dunia $60-90 \%$ anak sekolah mengalami karies ${ }^{5}$. Di Indonesia 28,9\% anak Indonesia usia 5-9 tahun mengalami masalah gigi dan mulut ${ }^{6}$, sedangkan di provinsi Sumatera Barat menunjukkan 23,5\% anak usia 5-9 tahun mengalami masalah kesehatan gigi dan mulut ${ }^{7}$. Sebagian besar anak-anak tidak menyadari dan tidak tahu pentingnya menjaga kesehatan gigi dan mulut dikarenakan anak-anak masih sangat bergantung pada orang tua dalam menjaga kesehatan gigi dan mulut. Dalam perubahan perilaku terdapat tiga domain penting meliputi pengetahuan, sikap, dan tindakan. Perilaku mulai terbentuk dari pengetahuan, kemudian pengetahuan menstimulus perubahan sikap dan tindakan 8

Berdasarkan penelitian Hastuti (2010) pada anak SD di Kecamatan Sambi Kabupaten Boyolali pengetahuan anak tentang kesehatan gigi berada pada tingkatan buruk dan kurang dan hasil penelitian Afif Hamdalah (2013) pada siswa SDN 2 Patrang Kabupaten jember tentang pengetahuan siswa mengenai kesehatan gigi hanya $11,54 \%$ responden memiliki pengetahuan tinggi. Pengetahuan kesehatan gigi dan mulut yang rendah pada anak merupakan salah satu faktor penyebab terjadinya karies. Pengetahuan anak tentang karies berhubungan dengan terjadinya penyakit karies. Oleh karena itu, diperlukan suatu upaya untuk peningkatan pengetahuan anak tentang kesehatan gigi dan mulut agar dapat mengendalikan tingginya karies pada anak. Salah satu upaya meningkatkan pengetahuan dan mencegah masalah kesehatan gigi dan mulut pada anak adalah dengan upaya preventif dengan cara memberikan pendidikan kesehatan gigi dan mulut melalui penyuluhan ${ }^{9}$. Salah satu sasaran dari penyuluhankesehatan gigi dan mulut adalah anak-anak usia 8-11 tahun yang duduk di bangku kelas 3-5 Sekolah Dasar. Usia tersebut merupakan usia kritis 
terhadap terjadinya karies gigi permanen, karena masa transisi pergantian gigi susu ke gigi permanen diawali pada usia tersebut. Anak-anak juga cenderung mengkonsumsi makanan kariogenik seperti coklat, permen, dan kue-kue yang lengket, jika dikonsumsi berulang bisa mengakibatkan kerusakan pada gigi anak ${ }^{9}$.Dengan diberikannya penyuluhan tentang kesehatan gigi dan mulut pada usia tersebut anak-anak mengerti untuk menjaga kesehatan gigi agar tetap berfungsi dengan baik sampai usia tua. Anak-anak sebagai sasaran penyuluhan memiliki karakteristik tertentu sesuai dengan usia dan perkembangan kognitifnya. Anak usia 7-11 tahun berada pada tahap perkembangan operasional konkrit, yang sudah bisa menggunakan penalaran, memecahkan masalah nyata (konkret), dan memahami sebab akibat ${ }^{10}$. Sehingga metode, pendekatan, dan media yang digunakan untuk membantu proses pendidikan pada anak harus disesuaikan supaya apa yang disampaikan dapat diterima secara efektif dan penerima memahami materi pendidikan.

Metode penyuluhan dapat digunakan sebagai alat, strategi, dan motivasi peserta didik agar dapat dengan cepat menerima informasi. Terdapat berbagai metode untuk penyuluhan kesehatan diantaranya metode bermain peran $^{11}$, dan metode dongeng ${ }^{12}$. Dongeng adalah cerita fiktif sederhana yang tidak benar-benar terjadi yang berfungsi untuk mendidik juga menghibur ${ }^{13}$. Metode bercerita ini sangat berpengaruh dan disukai dalam pengajaran terhadap anak. Berdasarkan penelitian Mehrdad Ghaffari Targhi (2015) pada siswa SD dijelaskan bahwa metode dongeng memiliki efek yang lebih signifikan dibandingkan dengan metode ceramah terhadap perubahan pengetahuan, sikap dan praktek dalam pendidikan kesehatan gigi dan mulut. Hasil penelitian Raafi'ud Darajat (2012) pada siswa SD penggunaan metode dongeng dapat meningkatkan pengetahuan $61 \%$ siswa yang mengikuti penyuluhan. Bermain merupakan suatu kegiatan dengan atau tanpa menggunakan sesuatu dimana diberikan kesenangan, informasi, dan imajinasi terhadap sesuatu tersebut ${ }^{14}$.Hasil penelitian oleh Makuch (2001) pada anakanak SD di Inggris menunjukkan bahwa metode bermain telah menjadi pelopor kesehatan dalam promosi kesehatan gigi dan mulut. Salah satu metode bermain yaitu metode bermain peran. Berdasarkan penelitian Shilpa dan Swamy (2015) pada siswa Sekolah Dasar bermain peran merupakan strategi pendidikan yang efektif dalam menanamkan pengetahuan kesehatan gigi dan mulut pada anak Sekolah Dasar. Hasil penelitian Astuti (2014)pada anak SD metode bermain peran (Role Play) lebih efektif 
dibandingkan dengan metode dongeng (Storytelling) dalam meningkatkan prestasi siswa Sekolah dasar.

Berdasarkan laporan Dinas Kesehatan Kota Padang tahun 2015 menunjukkan Puskesmas Andalas dengan kasus karies terbanyak yaitu 662 kasus karies dari dua puluh dua puskesmas di kota Padang. Hasil screening Puskesmas Andalas pada seluruh sekolah binaan Puskesmas Andalas menunjukkan SDN 22 Andalas Padang memiliki angka kejadian karies tertinggi yaitu sebanyak 50 kasus. Anak-anak kelas 3 Sekolah Dasar berada pada masa transisi tumbuh kembang gigi dan perkembangan kognitif operasional konkret, masa ini disebut perkembangan intelektual dan pada usia ini daya ingatan anak mencapai intensitas terbesar, terbaik, dan terkuat 10 dan siswa kelas 3 Sekolah Dasar umumnya masih menggunakan kurikulum 2006 sedangkan kelas 4 Sekolah Dasar sudah menggunakan kurikulum 2013. Sejauh yang peneliti ketahui belum ada penelitian yang serupa dengan yang akan peneliti lakukan. Berdasarkan uraian diatas penulis tertarik untuk meneliti perbandingan efektifitas penyuluhan kesehatan gigi dan mulut metode dongeng (storytelling) dengan metode bermain peran (role play) pada siswa kelas 3 SD.

\section{METODE}

Jenis penelitian yang digunakan adalah penelitian quasi eksperimental dengan jumlah sampel sebanyak 54 orang siswa kelas 3 SDN 22 Andals Kota Padang. Penelitian ini difokuskan untuk membandingkan perbedaan peningkatan pengetahuan siswa tentang kesehatan gigi melalui metode dongeng (storytelling) dan metode bermain peran (role play).

Pengumpulan data dari responden penelitian untuk dicocokkan dengan kriteria penelitian. Penelitian ini dibagi atas dua kelompok yaitu kelompok metode dongeng (storytelling) dan kelompok bermain peran (role play). Penelitian dilakukan pada tempat yang berbeda untuk masing-masing kelompok. Pada saat hari penelitian, peneliti menjelaskan maksud dan tujuan peneliti. Setelah itu, peneliti meminta siswa yang bersedia mengikuti penyuluhandan wali kelas pada masingmasing kelompok untuk mengisi lembar persetujuan mengikuti penelitian, serta peneliti melakukan pre test pada siswa tentang kesehatan gigi dan mulut. Pengumpulan dilakukan langsung setelah pemberian pre test tanpa memberi tahu masing-masing kelompok akan diberikan post test. Masing-masing kelompok diberikan pendidikan kesehatan dengan metode dongeng (storytelling) atau bermain peran (role play) sesuai dengan kelompoknya. Pada kelompok metode 
dongeng, responden penelitian hanya sebagai pengamat selama penceritaan dongeng. Pada kelompok bermain peran, responden penelitian berperan aktif menjadi tokoh-tokoh yang ada di skenario bermain peran. Responden akan dibagi menjadi 7 kelompok, masing-masing kelompok terdiri dari 4 orang untuk memerankan 4 karakter tokoh sesuai skenario. Pada masing-masing kelompok setelah 20 menit diberikan penyuluhan kesehatan dan mulut dilakukan post test dengan pertanyaan yang sama pada masing-masing kelompok. Semua hasil post test pada subjek masing-masing kelompok dikumpulkan. Pengolahan data dan analisa

\section{HASIL PENELITIAN}

Tabel 5.1 Karakteristik Responden Berdasarkan Umur

\begin{tabular}{lcccc}
\hline Umur & \multicolumn{3}{l}{ SDN 22 Andalas (A) } & \multicolumn{3}{c}{ SDN 22 Andalas (B) } \\
\cline { 2 - 5 } & $n$ & $\%$ & $n$ & $\%$ \\
\hline 8 tahun & 6 & 22 & 5 & 18 \\
8 tahun & 18 & 68 & 20 & 74 \\
10 tahun & 3 & 11 & 2 & 7 \\
\hline Jumlah & 27 & 100 & 27 & 100 \\
\hline
\end{tabular}

Data diatas menunjukkan responden terbanyak dari jumlah responden adalah umur 9 tahun yang berjumlah 38 orang.

Tabel 5.2 Karakteristik Responden Berdasarkan Jenis Kelamin

\begin{tabular}{lcccc}
\hline \multicolumn{1}{c}{ Kelamin } \\
Jenis & SDN 22 Andalas (A) & SDN 22 Andalas (B) \\
\cline { 2 - 5 } Kelamin & $n$ & $\%$ & $n$ & $\%$ \\
\hline Laki-Laki & 14 & 52 & 12 & 44 \\
Perempuan & 13 & 48 & 15 & 56 \\
\hline Jumlah & 27 & 100 & 27 & 100 \\
\hline
\end{tabular}

Data diatas menunjukkan responden terbanyak adalah yang perempuan yang berjumlah 28 orang.

Tabel 5.3 Tingkat Pengetahuan Sebelum Dan Setelah Penyuluhan Dengan Metode Dongeng (Storytelling) (Hasil Uji Paired T Test)

Kelas 3A n rata-ratatStd $\Delta x \pm$ Std $\quad$ IC $95 \quad P$

Pre Test $27 \quad 64,81 \pm 10,33 \quad 14,26 \pm 4,09 \quad 12,64 \pm 15,88 \quad 0,000$

\section{Post Test $2779,07 \pm 10,00$}

Berdasarkan tabel hasil uji paired $T$ test di atas didapatkan nilai rata-rata pre test adalah 64,81 , dan nilai rata-rata post test adalah 79,07. Perbedaan nilai pre test dan post test sebesar 14,26. Tabel diatas juga menunjukkan nilai $\mathrm{p}=0,000$, karena nilai $\mathrm{p}<0,05$ maka dapat disimpulkan terdapat perbedaan yang signifikan antara hasil pre test dan post test penyuluhan kesehatan gigi dengan metode dongeng (storytelling).

Tabel 5.4 Tingkat Pengetahuan Sebelum Dan Setelah Penyuluhan Dengan Metode Bermain Peran (Role Play) (Hasil 
Uji Paired T Test) Kelas 3B n rata$\operatorname{rata} \pm \operatorname{Std} \Delta \mathrm{x} \pm$ Std IC $95 \% \mathrm{p}$ Pre Test 27 $68,89 \pm 10,13 \quad 17,96 \pm 3,99 \quad 16,39 \pm 19,54$ 0,000 Post Test $27 \quad 86,85 \pm 9,32$ Berdasarkan tabel hasil uji paired T test di atas didapatkan nilai rata-rata pre test adalah 68,89, dan nilai rata-rata post test adalah 86,85 . Perbedaan nilai pre test dan post test sebesar 17,96. Tabel diatas juga menunjukkan nilai $\mathrm{p}=0,000$, karena nilai $\mathrm{p}$ $<0,05$ maka dapat disimpulkan terdapat perbedaan yang signifikan antara hasil pre test dan post test penyuluhan kesehatan gigi dengan metode bermain peran (role play).

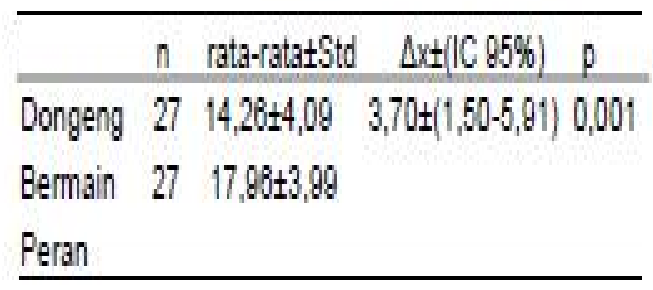

Berdasarkan tabel hasil uji independen $T$ test didapatkan perbedaan nilai rata-rata 3,70 antara metode dongeng (storytelling) dan metode bermain peran (role play). Dari uji homogenitas menggunakan tes levene menunjukkan hasil $\mathrm{p}=0,697$, yang artinya kedua kelompok varian sama karena nilainya tes levene $\mathrm{p}>0,05$. Berdasarkan tabel diatas didapatkan nilai $\mathrm{p}=0,001$, karena nilai $\mathrm{p}<$ 0,05 maka dapat disimpulkan Ho ditolak dan Ha diterima yang artinya terdapat perbedaan peningkatan nilai rata-rata sebelum dan setelah penyuluhan kesehatan gigi menggunakan metode dongeng (storytelling) pada kelas IIIA dan metode bermain peran (role play) pada kelas IIIB.

\section{PEMBAHASAN Analisis Univariat}

Secara keseluruhan data persebaran umur subjek penelitian yang berumur 8 tahun sebanyak 20,37\%, berumur 9 tahun sebanyak 70,37\%, dan berumur 10 tahun sebanyak 9,26\%. Anak usia 8-10 tahun berada pada masa perkembangan kognitif operasional konkret dimana pada tahap ini merupakan tahap perkembangan intelektual dan daya ingat anak mencapai intensitas terbesar, terkuat, dan terbaik. Pada usia 8-10 tahun anak tidak lagi bersifat egosentris dimana anak telah dapat menerima pendapat orang lain ${ }^{10}$.

\section{Analisis Bivariat}

1. Pengetahuan Siswa Sebelum Dan Setelah Diberikan Penyuluhan Kesehatan Gigi Dengan Metode Dongeng (Storytelling) Hasil penelitian menunjukkan terjadi peningkatan pengetahuan kesehatan gigi setelah diberikannya penyuluhan kesehatan gigi menggunakan metode dongeng (storytelling). Penggunaan metode dongeng (storytelling) sebagai alat bantu penyuluhan kesehatan gigi pada siswa kela IIIA SDN 22 Andalas kota Padang menunjukkan nilai rata-rata pengetahuan sebelum diberikan penyuluhan adalah 
64,81 dan setelah diberikan penyuluhan menjadi 79,07. Peningkataan pengetahuan yang terjadi setelah diberikan penyuluhan dengan metode dongeng hal ini karena pada usia 8-10 tahun anak-anak menyukai cerita-cerita15. Dongeng merupakan cerita fiktif sederhana yang berfungsi untuk menghibur juga mendidik ${ }^{13}$, dengan mendongeng anak diberikan kesenangan dan pendidikan melalui alur cerita yang dibawakan. Pemberian penyuluhan dengan metode dongeng tepat digunakan pada anak-anak SD karena dengan bercerita dapat meningkatkan daya pikir dan pengembangan imajinasi pada anak ${ }^{16}$. Dongeng dapat membantu perkembangan kepribadian anak, dengan dongeng anak dapat memperoleh pemahaman bagaimana konflik-konflik yang dibangun dan tokoh yang ditampilkan memecahkan masalah yang serupa dengannya. Dongeng merupakan media yang efektif untuk menanamkan nilai moral, sosial dan etika kepada anak, maupun tentang berbagai kebiasaan sehari-hari seperti pentingnya makan sayur dan menggosok gigi. Seringkali dongeng menjadi inspirasi bagi seorang anak dalam bertingkah laku dan bercita-cita.Melalui dongeng, jelajah cakrawala pemikiran anak akan menjadi lebih baik, lebih kritis, dan lebih cerdas. Anak dapat membentuk visualisasinya sendiri dari cerita dongeng yang didengarkan ${ }^{17}$.
Hasil penelitian ini didukung oleh hasil penelitian sebelumnya yang dilakukan oleh Mehrdad Ghaffari Targhi (2015) pada siswa SD yang menjelaskan bahwa metode dongeng memiliki efek yang lebih signifikan terhadap perubahan pengetahuan, sikap, dan praktek dalam pendidikan kesehatan gigi dan mulut dibandingkan dengan metode ceramah

2. Pengetahuan Siswa Sebelum Dan Setelah Diberikan Penyuluhan Kesehatan Gigi Dengan Metode Bermain Peran (Role Play) Penggunaan metode bermain peran sebagai alat bantu penyuluhan kesehatan gigi pada sisiwa kelas IIIB SDN 22 Andalas menunjukkan peningkatan ratarata nilai pengetahuan sebelum diberikan penyuluhan adalah 68,89 dan setelah diberi penyuluhan rata-rata nilai pengetahuan siswa adalah 86,85. Metode Role Play adalah cara penyuluhan yang menarik dan efektif bagi peserta didik dengan menampilkan situasi-situasi cerita yang nyata $^{18}$. Metode penyuluhan dengan bermain peran merupakan metode yang aktif, kreatif, efektif, dan menyenangkan ${ }^{19}$. Penyuluhan dengan metode bermain peran efektif digunakan pada anak usia 8-10 tahun karena pada usia ini anak tidak lagi bersifat egosentris sehingga anak dapat bekerjasama dalam melakonkan peranperan di skenario ${ }^{10}$.Metode bermain peran dapat meningkatkan hasil belajar anak sekolah dasar mencapai $92,30 \%{ }^{20}$. 
Metode bermain peran merupakan salah satu metode yang dipilih dalam proses pembelajaran di kelas karena memiliki daya tarik tersendiri bagi siswa sebab biasanya siswa sangat antusias terhadap pelajaran yang menyangkut kehidupan sehari-hari dikalangan masyarakat. Metode ini berhubungan dengan penghayatan suatu peranan sosial yang dimainkan anak di masyarakat ${ }^{21}$. Penyuluhan dengan metode bermain peran semua peserta dapat ikut aktif mengamati, mengalami, dan menghayati perilakuperilaku tertentu sehingga suasana penyuluhan menjadi lebih hidup dan tumbuh sikap kritis dari sasaran ${ }^{22}$. Bermain peran umumnya dapat memotivasi dan menginspirasi siswa dari kegiatan tokoh yang diperankan ${ }^{18}$. Metode penyuluhan dengan bermain peran sesuai dengan karakteristik anak sekolah dasar yang senang bermain, mengobservasi, dan mengeksplorasi suatu situasi. Dengan metode bermain peran anak diberi kesempatan untuk mengembangkan imajinasinya dalam penghayatan memerankan tokoh di skenario Hasil penelitian ini didukung oleh penelitian sebelumnya yang dilakukan oleh Mrs Shilpa PM dan Mr Swamy PGN (2015) bermain peran merupakan strategi pendidikan yang efektif dalam menanamkan pengetahuan kesehatan gigi dan mulut pada anak Sekolah Dasar.
Metode bermain juga telah menjadi pelopor kesehatan dalam promosi kesehatan gigi dan mulut bagi siswa SD di Inggris ${ }^{23}$.

3. Perbedaan Perubahan Tingkat Pengetahuan Kesehatan Gigi Pada Siswa Yang Diberikan Penyuluhan Dengan Metode Dongeng (Storytelling) Dan Metode Bermain Peran (Role Play)

Untuk melihat perbedaan digunakan uji independent $T$ test. Berdasarkan hasil uji independent $T$ test yang dilakukan pada kedua kelompok yaitu kelompok metode dongeng (storytelling) dan kelompok metode bermain peran (role play), menunjukkan bahwa nilai $\mathrm{p}=0,001$, dengan syarat yang berlaku yaitu jika nilai $\mathrm{p}<0,05$ maka dapat disimpulkan Ho ditolak dan $\mathrm{Ha}$ diterima yang artinya terdapat perbedaan peningkatan selisih nilai rata-rata sebelum dan setelah penyuluhan kesehatan gigi menggunakan metode dongeng (storytelling) pada kelas IIIA dan metode bermain peran (role play) pada kelas IIIB. Rata-rata peningkatan pengetahuan menggunakan metode dongeng (storytelling) adalah 14,26, sedangkan rata-rata peningkatan pengetahuan siswa yang menggunakan metode bermain peran (role play)adalah 17,96. Untuk masingmasing kelompok menunjukkan hasil perubahan tingkat pengetahuan yang 
signifikan. Diantara kedua metode penyuluhan terdapat perbedaan yang memungkinkan untuk mempengaruhi hasil peningkatan pengetahuan dari kedua kelompok. Padakedua metode penyuluhan terdapat isi materi yang sama, yang membedakannya adalah dalam hal penyajian materi. Penyajian materi pada metode dongeng (storytelling) subjek penelitian hanya sebagai pengamat dan pendengar sedangkan pada metode bermain peran (role play) subjek penelitian dituntut untuk memerankan karakter tokoh dalam skenario.

Hasil penelitian ini menunjukkan bahwa metode bermain peran (role play) sebagai metode penyuluhan kesehatan gigi menunjukkan hasil peningkatan yang lebih tinggi dibandingkan dengan metode dongeng (storytelling).Hal ini dapat disebabkan oleh dengan bermain peran anak ikut aktif dalam penyuluhan sedangkan dengan dongeng anak-anak hanya pasif sebagai pendengar. Bermain peran dapat memotivasi dan menginspirasi siswa dari kegiatan tokoh yang diperankan ${ }^{18}$.Karakteristik anak sekolah dasar diantaranya siswa suka bermain, mengeksplorasi suatu situasi, dan mengobservasi suatu situasi ${ }^{19}$. Metode bermain peran dapat meningkatkan minat belajar siswa dalam mengikuti suatu proses pembelajaran 21. Pada teori piramida Edgar Dale bermain peran berada pada urutan 10 sedangkan metode dongeng berada pada urutan ke 6dari puncak piramida. Berdasarkan teori Edgar Dale semakin jauh posisi metode pembelajaran dari puncak piramida semakin efektif metode pembelajaran tersebut. Sehingga dengan mengaktualisasikan cerita dapat meningkatkan pemahaman dan daya ingat dari materi penyuluhan yang diberikan ${ }^{24}$.Dalam menerima penyuluhan dengan metode yang diberikan terdapat faktor internal seperti minat, bakat, kesiapan, dan pengalaman serta faktor eksternal seperti keluarga, sekolah, dan masyarakat yang berpengaruh terhadap kemauan responden dalam menerima dan melakukannya ${ }^{22}$.

\section{KESIMPULAN}

1. Penggunaan metode dongeng (storytelling) sebagai metode penyuluhan menunjukkan hasil yang signifikan terhadap peningkatan pengetahuan kesehatan gigi pada siswa kelas IIIA di SDN 22 Andalas Kota Padang.

2. Penggunaan metode bermain peran (role play) sebagai metode penyuluhan menunjukkan hasil yang signifikan terhadap peningkatan pengetahuan kesehatan gigi pada siswa kelas IIIB di SDN 22 Andalas Kota Padang. 
3. Peningkatan pengetahuan kesehatan gigi pada siswa kelas 3 yang diberi penyuluhan dengan metode bermain peran (role play) menunjukkan hasil yang lebih tinggi dibandingkan dengan penyuluhan dengan metode dongeng (storytelling).

\section{KEPUSTAKAAN}

1. Lossu,Fara M. Damajanty H.C. Pangemanan dan Vonny N.S Wowor. 2015. Hubungan Pengetahuan Kesehatan Gigi Dan Mulut Dengan Indeks Gingiva Siswa SD Katolik 03 Frater Don Bosko Manado.Jurnal e GiGi (eG) Vol.3, No.2, Juli-Desember 2015.

2. Kemenkes RI.Situasi Gigi dan Mulut.InFoDATIN : $2007 \& 2013$

3. Sheiham,Aubrey dan Marcelo Bonecker.2006.Promoting Children's Oral Health Theory \&

Practice.Brasil:Quintessence Editor Lida

4. Departemen Kesehatan RI (2007). Laporan Hasil Riset Kesehatan Dasar (RISKESDAS) Nasional. Jakarta: LITBANG DEPKES RI

5. World Health Organization. 2007. Media Centre Oral Health. http://www.who.int/mediacentre/factsheet s/fs318/en/index.html. diakses Desember 2016.

6. Departemen Kesehatan RI (2013). Laporan Hasil Riset Kesehatan Dasar (RISKESDAS) Nasional. Jakarta: LITBANG DEPKES RI

7. Departemen Kesehatan RI (2013). Laporan Hasil Riset Kesehatan Dasar
(RISKESDAS) Sumatera Barat. Jakarta: LITBANG DEPKES RI

8. Maulana, Heri D.J. 2013. Promosi Kesehatan. Jakarta:EGC (Nurhidayat dkk.,2012)

9. Nurhidayat,Oki. Eram Tunggul $\mathrm{P}$ dan Bambang Wahyono.2012. Perbandingan Media Power Point Dan Flip Chart Dalam Meningkatkan Pengetahuan Kesehatan Gigi Dan Mulut.Unnes Journal of Public Health (1) (2012) ISSN 2252-6781.

10. Papalia,Diane E. Sally Wendkos Olds dan Ruth Duskin Feldman.2013.Human Development.Salemba. Jakarta : Humanica edisi 10

11. Setiawati,S dan A.C Dermawan.2008.Proses Pembelajaran Dalam Pendidikan Kesehatan.Jakarta: Trans Info Media

12. Mancoro, Nurliatin. 2015. Peningkatan Kemampuan Berbicara Melalui Dongeng Dalam Pembelajaran Bahasa Indonesia Siswa Kelas I SDN 2 Tatura. Jurnal Kreatif Tadulako Online Vo.4 No.4 ISSN 2354-614X.

13. Willox, Ashlee Cunsolo. Sherille L Harper dan Victoria L Edge.2013.Storytelling In Digital Age: Digital Storytelling As An Emerging Narrative Method For Preserving And Promotion Indigenous Oral Wisdom.Qualitative Research 13(2) 127-147.SAGE.March 28,2013

14. Sumantri,Dedi. Yuniar Lestari dan Mustika Arini. 2012.Pengaruh Perubahan Tingkat Pengetahuan Gigi Dan Mulut Pada Pelajar Usia 7-8 Tahun Di 2 Sekolah Dasar Kecamatan Mandiangin Koto Selayan Kota Bukittinggi Melalui Permainan Edukasi Kedokteran Gigi.Andalas Dental Journal 
15. Singgih, Gunarsa.2008.Dasar dan Teori Perkembangan Anak. Jakarta: Gunung Mulia.

16. Ningsih,Suwarti.2013.Peningkatan Keterampilan Berbicara Melalui Metode Berceritasiswa Kelas 3 SD Negeri 1 Beringin Jaya Kecamatan Bumi Raya Kabupaten Morowali. Jurnal kreatif taduluko online vol 2 no.4 ISSN 2354$614 X$.

17. Ipriansyah.2011.Peran Dongeng Bagi Perkembangan Pembentukan Kepribadian Anak.Jurnal Ta'dib Vol.XVI, No.01, Edisi Juni 2011.

18. Shilpa,PM dan Swamy,PGN.2015. A Study To Evaluate The Effectiveness Of Role Play On Knowledge Regarding Oral Hygiene Among Higher Primary School Children In Selected School At Tumkur. Journal Of Nursing And Health Science Volume 4,Issue 2 Ver. 1 (Mar-Apr. 2015) PP 37-42

19. Simatupang,Syawal.2011.Pengaruh

Penerapan Metode Pembelajaran Bermain Peran Terhadap Kompetensi Sosial Kognitif Siswa.Pekbis Jurnal,Vol.3 No.2 Juli 2011:504-511
20. Aliakhir, Hijria A. Muh.Tahir. Dan Saharudin Barsandji. 2014. Penerapan Metode Bermain Peran Pada Materi Drama Anak Untuk Meningkatkan Hasil Belajar Siswa Kelas 3 SDN Gio. Jurnal Kreatif Tadulako Online Vol.4 No. 5 ISSN 2354-614X

21. Kartini, Tien. 2007. Penggunaan Metode Role Playing Untuk Meningkatkan Minat Siswa Dalam Pembelajaran Pengetahuan Sosial Di Kelas V SDN Cileunyi I Kecamatan Cileunyi Kabupaten Bandung. Jurnal, Pendidikan Dasar Nomor 8 Oktober 2007.

22. Herijulianti, Eliza. Tati Svasti Indriani dan Sri Artini..2002. Pendidikan kesehatan gigi. Jakarta:EGC.

23. Makuch Almut dan Recshke Konrad.2001. Playing Games In Promoting Childhood Dental Health Patient Education And Counseling.Patient Education and Conseling43.2001;105-110.

24. 24. Ali, Zaidin,2010. Dasar-Dasar Pendidikan Kesehatan Masyarakat Dan Promosi Kesehatan. Jakarta : Trans Info Med 